\title{
Analysis of continuous first-line treatment with docetaxel and carboplatin for advanced non-small cell lung cancer
}

\author{
TAKUYA AOKI $^{1}$, AKINORI EBIHARA ${ }^{1}$, YURIKA YOGO ${ }^{2}$, KEIICHI SUEMASU $^{3}$ and FUMIO SAKAMAKI $^{2}$ \\ ${ }^{1}$ Division of Respiratory Medicine, Department of Internal Medicine, Tokai University School of Medicine, Isehara, \\ Kanagawa 259-1193; ${ }^{2}$ Division of Respiratory Medicine, Department of Internal Medicine; \\ ${ }^{3}$ Department of Thoracic Surgery, Saiseikai Central Hospital, Minato-ku, Tokyo 108-0073, Japan
}

Received August 14, 2013; Accepted February 18, 2014

DOI: $10.3892 / \mathrm{ol} .2014 .1973$

\begin{abstract}
The present study aimed to analyze the efficacy and safety of multiple cycles of docetaxel and carboplatin (CBDCA) as a first-line treatment in patients with advanced non-small cell lung cancer (NSCLC). Patients with stage III or IV NSCLC, whose treatment began between July 1999 and February 2003, were retrospectively evaluated. Relatively low doses of docetaxel and CBDCA were administered for as many cycles as possible. The primary outcome assessed was the overall survival (OS) time, and the secondary outcomes included progression-free survival (PFS) time, response rate (RR) and adverse events. The median cycle number was four (range, 2-12). The median OS time was 400 days, and for adenocarcinoma and non-adenocarcinoma, the OS time was 490 and 192 days, respectively. The median PFS time was 176 days and the RR was $66.7 \%$. The main toxicity of the treatment was neutropenia, with grade 3 or 4 neutropenia occurring in $81.0 \%$ of patients. Continuous first-line treatment with this regimen may have encouraging effects within a certain group of advanced NSCLC patients, thereby warranting further investigations.
\end{abstract}

\section{Introduction}

For almost 20 years lung cancer has been the most frequent malignancy worldwide, and it remains the most common cause of cancer mortality (1,2). A large amount of evidence supports the use of chemotherapy as a first-line therapy in advanced non-small cell lung cancer (NSCLC) patients with a good performance status (PS). This is founded on a landmark meta-analysis that demonstrated the reduced risks of mortality

Correspondence to: Dr Takuya Aoki, Division of Respiratory Medicine, Department of Internal Medicine, Tokai University School of Medicine, 143 Shimokasuya, Isehara, Kanagawa 259-1193, Japan

E-mail: aokitaku@is.icc.u-tokai.ac.jp

Key words: continuous first-line treatment, docetaxel, carboplatin, efficacy, safety and an increased one-year survival rate following chemotherapy (3). The current standard first-line therapy consists of platinum combinations of two cytotoxic drugs with or without a molecular-targeted agent $(4,5)$.

The optimal duration of first-line chemotherapy for patients with stage IV NSCLC has yet to be established. Socinski et al (6) demonstrated that continuing treatment with carboplatin (CBDCA) and paclitaxel beyond four cycles produced no overall benefit in survival time, response rates or quality of life for patients with advanced NSCLC. However, the data are limited. According to the 2011 focused update of the 2009 American Society of Clinical Oncology (ASCO) clinical practice guideline (7), first-line cytotoxic chemotherapy should be discontinued when disease progression has been detected or following four cycles in patients whose disease is stable but is not responding to treatment. For the patients with stable disease (SD), or for those who show a response following four cycles of treatment, immediate treatment with an alternative, single-agent chemotherapy, including pemetrexed, docetaxel or erlotinib, may be administered. Following a fixed course of treatment, a break from cytotoxic chemotherapy is also acceptable, however, second-line chemotherapy is initiated upon disease progression.

Despite the development of various first-line therapies with a fixed course of treatment, the outcomes remain poor. Two varying types of chemotherapy for the continuation of treatment soon after stopping the platinum-based doublet regimens have been extensively investigated. One is continuation maintenance therapy, which involves continuing an agent that was part of the initial induction treatment regimen (8-10), while the other is switch maintenance therapy that involves initiating another agent prior to disease progression (10-15). The approximate median progression-free survival (PFS) time with these therapeutic approaches ranged between 3 and 5 months following maintenance therapy initiation, and between 6 and 7 months following induction therapy initiation, although patients showing progressive disease (PD) with the first-induction therapy were excluded (8-15).

One of the major variations between first-line platinum doublet combinations and maintenance therapies is feasibility. Continuation of a first-line platinum doublet regimen may be difficult, even when the regimen is effective, due to toxicity. Feasible first-line platinum doublet combinations 
could be continued beyond standard cycle numbers and may exert favorable effects if cumulative toxicities do not occur or can be managed without deterioration of the PS. It is, however, extremely difficult to perform a prospective study on continuous multiple-cycle first-line treatments under the present circumstances. However, the cycle number of first-line treatment was not strictly determined until 2003 (16). The present study retrospectively analyzed the efficacy and safety of continuous multiple-cycle first-line treatment with CBDCA and docetaxel in advanced NSCLC patients whose treatment had been initiated during the period between July 1999 and February 2003.

\section{Materials and methods}

Patient selection. Between July 1999 and February 2003, NSCLC patients who met the established criteria were treated with docetaxel plus CBDCA at Saiseikai Central Hospital (Tokyo, Japan), according to the selected treatment schedule. In total, a case series of 21 patients (17 males and 4 females) with inoperable stage IIIB and IV NSCLC without prior chemotherapy were evaluated. The medical data collected up to July 2004 was assessed. The primary outcome was overall survival (OS) time, and the secondary outcomes included PFS, response rate (RR) and adverse events. The retrospective protocol was approved by the institutional review boards of the Tokai University School of Medicine (Isehara, Japan) and the Saiseikai Central Hospital (Tokyo, Japan).

The selection criteria for the patients were as follows: Histologically or cytologically proven NSCLC; an Eastern Cooperative Oncology Group PS of 0,1 or 2 ; an age of $\geq 18$ years; measurable lesions as assessed by computed tomography (CT); adequate bone marrow reserves, defined as a white blood cell (WBC) count of $\geq 3,500 / \mu 1$, a neutrophil count of $\geq 2,000 / \mu 1$, a platelet count of $\geq 100,000 / \mu 1$ and hemoglobin levels that were $\geq 10 \mathrm{~g} / \mathrm{dl}$; and adequate liver function, defined as bilirubin levels of $<2.0 \mathrm{mg} / \mathrm{dl}$ and/or aspartate transaminase (AST), alanine transaminase (ALT) and $\gamma$-glutamyltransferase levels at more than three times the upper limit of normal. Patients with impaired renal function were included if the measured creatinine clearance was $>40 \mathrm{ml} / \mathrm{min}$. Patients with ischemic heart diseases and diabetes mellitus were included if their conditions were medically controlled, and those who had central nervous system metastasis were also included. None of the patients had undergone previous radiation therapy or major surgery. Patients with malignant pleural and/or pericardial effusions were also included. Patients with stage IIIB disease who could be treated with curative radiotherapy were excluded.

Treatment schedule. Prior to starting chemotherapy, all the patients underwent a physical examination, a complete blood count, blood and urine chemistry, a chest X-ray, a chest CT scan, an abdominal echo and/or CT scan, a head CT and/or MRI, a bone scan and electrocardiography. The creatinine clearance was measured, and complete blood cell counts, differential counts and routine blood chemistry measurements were performed at least twice weekly during the first cycle. On the day of the nadir following the initiation of chemotherapy, the minimum WBC and neutrophil and platelet counts were determined. The patients were hospitalized during all the chemotherapy courses and evaluated by physical examination, complete blood count, blood chemistry and a chest X-ray. The responses were assessed every two cycles by a chest X-ray and/or a CT scan, and metastasis was also evaluated.

All the patients received the following treatment protocol: $60 \mathrm{mg} / \mathrm{m}^{2}$ docetaxel as a 3-h infusion in $500 \mathrm{ml}$ of $5 \%$ glucose or $0.9 \%$ saline, followed by $300 \mathrm{mg} / \mathrm{m}^{2} \mathrm{CBDCA}$ as a 2 -h infusion in $500 \mathrm{ml}$ of $5 \%$ glucose or $0.9 \%$ saline solution on day 1 . Antiemetic treatment with 5-hydroxytryptamine-3 antagonists was provided prior to the administration of chemotherapy. Steroids were not administered as premedication. The treatment was repeated every three to four weeks, provided that the patients had sufficiently recovered from any toxicities. The patients were treated with the same regimen as many times as possible unless there was evidence of PD, unacceptable toxicity or they refused further treatment. Once PD occurred following the initiation of the first-line treatment, second-line treatment began if the patient wanted to continue. The patients with a brain metastasis received either $\gamma$-knife radiosurgery or whole-brain radiotherapy. The patients with symptomatic bone metastasis and invasion were also treated with radiotherapy.

Recombinant human granulocyte colony-stimulating factor (G-CSF) was not administered prophylactically in the first cycle. G-CSF was administered at a dose of $1 \mu \mathrm{g} / \mathrm{kg}$ when the neutrophil counts were $<500 / \mathrm{mm}^{3}$, the febrile neutrophil counts were $<1,000 / \mathrm{mm}^{3}$ or the leukocyte counts were $<2,000 / \mathrm{mm}^{3}$. The patients who experienced grade 4 neutropenia received prophylactic G-CSF administration and the CBDCA dose was reduced by $25 \%$ in subsequent courses. The docetaxel dose was reduced by another $25 \%$ to ameliorate the neutropenia, as necessary. If the measured creatinine clearance was between 40 and $50 \mathrm{ml} / \mathrm{min}$, the CBDCA dose was reduced by $25 \%$.

Response and toxicity evaluation. The responses were assessed using Response Evaluation Criteria in Solid Tumors (version 1.0) (17). The confirmation of a complete response (CR) or partial response (PR) was required at least 4 weeks subsequent to the initial documentation. SD was defined as disease control (absence of progression) when it was maintained for at least 6 weeks. Toxicity was graded according to the National Cancer Institute's Common Toxicity Criteria for Adverse Events, version 3.0 (18).

Statistical analysis. PFS time was defined as the time that elapsed between the first day of the first-line therapy and the date of PD or mortality. The OS time was defined as the elapsed time between the first day of the first-line therapy and the date of mortality. The PFS and OS time differences between the groups were analyzed using the Kaplan-Meier method and compared using the log-rank test. Differences were considered to indicate a statistical significance when $\mathrm{P}<0.05$.

\section{Results}

The patient characteristics are listed in Table I. Unspecified NSCLC included poorly-differentiated and non-specified carcinomas. All the patients had a PS of 0-2. The measured creatinine clearances were 40-50, 51-60, 61-80, 81-90 and $\geq 91 \mathrm{ml} / \mathrm{min}$ in three $(14.3 \%)$, four $(19.0 \%)$, four (19.0\%), five 
Table I. Patient characteristics.

\begin{tabular}{|c|c|}
\hline Characteristics & Value $(\%)$ \\
\hline Total patients, $\mathrm{n}$ & $21(100)$ \\
\hline \multicolumn{2}{|l|}{ Gender, $\mathrm{n}$} \\
\hline Male & $17(81.0)$ \\
\hline Female & $4(19.0)$ \\
\hline \multicolumn{2}{|l|}{ Age, years } \\
\hline Median & 65 \\
\hline Range & $46-77$ \\
\hline \multicolumn{2}{|l|}{ ECOG PS, n } \\
\hline 0 & $10(47.6)$ \\
\hline 1 & $4(19.0)$ \\
\hline 2 & $7(33.3)$ \\
\hline \multicolumn{2}{|c|}{ Creatinine clearance in $\mathrm{ml} / \mathrm{min}, \mathrm{n}$} \\
\hline $40-50$ & $3(14.3)$ \\
\hline $51-60$ & $4(19.0)$ \\
\hline $61-80$ & $4(19.0)$ \\
\hline $81-90$ & $5(23.8)$ \\
\hline$\geq 91$ & $5(23.8)$ \\
\hline \multicolumn{2}{|l|}{$\mathrm{AUC}^{\mathrm{a}}$ in $\mathrm{mg} / \mathrm{ml} \times \mathrm{min}, \mathrm{n}$} \\
\hline $2.5-3.0$ & $2(9.5)$ \\
\hline $3.1-4.0$ & $4(19.0)$ \\
\hline $4.1-4.5$ & $5(23.8)$ \\
\hline $4.6-5.0$ & $5(23.8)$ \\
\hline $5.1-6.0$ & $4(19.0)$ \\
\hline$\geq 6.1$ & $1(4.8)$ \\
\hline \multicolumn{2}{|l|}{ Histology, n } \\
\hline Adenocarcinoma & $14(66.7)$ \\
\hline Squamous cell carcinoma & $3(14.3)$ \\
\hline Large-cell carcinoma & $2(9.5)$ \\
\hline Unspecified NSCLC & $2(9.5)$ \\
\hline \multicolumn{2}{|l|}{ Clinical stage, $\mathrm{n}$} \\
\hline IIIB & $5(23.8)$ \\
\hline IV & $16(76.2)$ \\
\hline \multicolumn{2}{|c|}{ No. of organs with metastases, $n$} \\
\hline 0 (stage IIIB) & $5(23.8)$ \\
\hline 1 & $3(14.3)$ \\
\hline 2 & $6(28.6)$ \\
\hline$\geq 3$ & $7(33.3)$ \\
\hline
\end{tabular}

aAUC, vs . time curve, calculated by Calvert's formula. ECOG, Eastern Cooperative Oncology Group; AUC, area under curve; NSCLC, nonsmall cell lung cancer; PS, performance status.

(23.8\%) and five $(23.8 \%)$ patients, respectively. The median area under the plasma concentration vs. time curve (AUC) as calculated by employing Calvert's formula, with the measured creatinine clearance as the glomerular filtration rate, was $4.4 \mathrm{mg} / \mathrm{ml} \mathrm{x} \mathrm{min}$ (range, $2.8-6.1 \mathrm{mg} / \mathrm{ml} \mathrm{x} \mathrm{min}$ ). The calculated AUC (mg/ml x min) values were 2.5-3.0, 3.1-4.0, 4.1-4.5, 4.6-5.0, 5.1-6.0 and $\geq 6.1$ in two $(9.5 \%)$, four $(19.0 \%)$, five (23.8\%), five (23.8\%), four $(19.0 \%)$ and one $(4.8 \%)$ patient, respectively. The
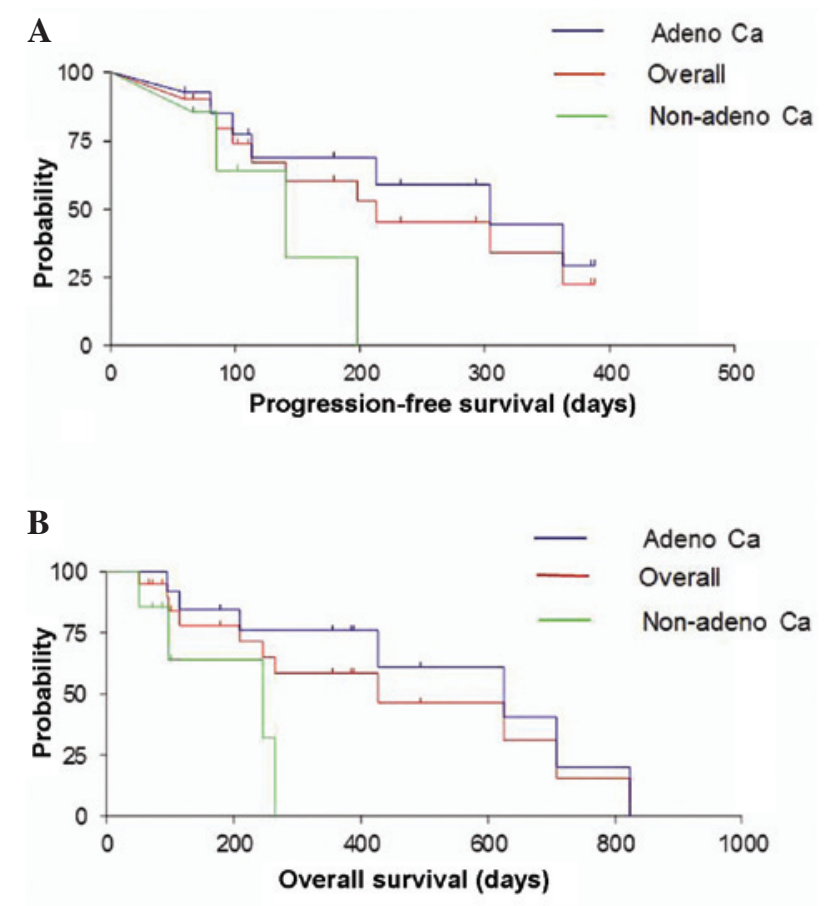

Figure 1. Cumulative Kaplan-Meier curves for (A) PFS and (B) OS, stratified according to tumor histology. Ca, carcinoma; PFS, progression-free survival; OS, overall survival.

vast majority of patients presented with adenocarcinoma and stage IV disease. All the patients were assessable for toxicity and response.

Fourteen patients achieved a PR (Table II). The overall RR was $66.7 \%$ [95\% confidence interval (CI), 43.0-85.4]. In total, five patients $(23.8 \%)$ had SD and two $(9.5 \%)$ had PD. The patients with adenocarcinoma had an RR of $64.3 \%$ (95\% CI, 35.1-87.2), and those with non-adenocarcinoma had an RR of 71.4\% (95\% CI, 29.0-96.3). The median number of cycles per patient was four (range, 2-12 cycles), and four patients received $\geq 10$ cycles and achieved long survival durations; 823 days (11 cycles), 625 days (10 cycles), 708 days (12 cycles) and 496 days (10 cycles).

The median OS time (Fig. 1) was 400 days (range, 52-1,047 days). For the adenocarcinoma patients the overall median survival time was 490 days (range, 95-1,047 days) and for the non-adenocarcinoma patients it was 192 days (range, 52-297 days). The log-rank test demonstrated a significant survival difference between the adenocarcinoma and non-adenocarcinoma patients $(\mathrm{P}=0.0012)$. The one-year survival rate was $47.6 \%(95 \% \mathrm{CI}$, 25.7-70.2) and the two-year survival rate was $9.5 \%(95 \% \mathrm{CI}$, 1.2-30.4). Among the adenocarcinoma patients, the one-year survival rate was $71.4 \%$ (95\% CI, 41.9-91.6) and the two-year survival rate was $14.3 \%$ (95\% CI, 1.8-42.8). The one-year survival rate was, however, $0 \%$ (95\% CI, 0-41.0) among the non-adenocarcinoma patients. The median PFS time (Fig. 1) for all the NSCLC patients was 176 days (range, 31-388 days), while the median PFS time was 210 days (range, 42-388 days) for the adenocarcinoma patients and 108 days (range, 31-198 days) for the non-adenocarcinoma patients. 
Table II. Responses according to patient characteristics.

\begin{tabular}{|c|c|c|c|c|c|c|c|}
\hline \multirow[b]{2}{*}{ Characteristics } & \multirow[b]{2}{*}{$\mathrm{n}$} & \multicolumn{4}{|c|}{ Response, $\mathrm{n}$} & \multirow[b]{2}{*}{$\mathrm{CR}+\mathrm{PR}, \%$} & \multirow[b]{2}{*}{$95 \% \mathrm{CI}$} \\
\hline & & $\mathrm{CR}$ & PR & $\mathrm{SD}$ & PD & & \\
\hline \multicolumn{8}{|l|}{ Histological subtypes, $\mathrm{Ca}$} \\
\hline Adeno & 14 & 0 & 9 & 4 & 1 & 64.3 & $35.1-87.2$ \\
\hline Non-adeno & 7 & 0 & 5 & 1 & 1 & 71.4 & $29.0-96.3$ \\
\hline Squamous cell & 3 & 0 & 3 & 0 & 0 & & \\
\hline Large cell/unspecified & 4 & 0 & 2 & 1 & 1 & & \\
\hline Overall & 21 & 0 & 14 & 5 & 2 & 66.7 & $43.0-85.4$ \\
\hline \multicolumn{8}{|c|}{ No. of chemotherapy cycles } \\
\hline 2 & 5 & 0 & 3 & 0 & 2 & & \\
\hline 3 & 3 & 0 & 0 & 3 & 0 & & \\
\hline 4 & 5 & 0 & 4 & 1 & 0 & & \\
\hline 6 & 1 & 0 & 1 & 0 & 0 & & \\
\hline 7 & 3 & 0 & 3 & 0 & 0 & & \\
\hline$\geq 10$ & 4 & 0 & 3 & 1 & 0 & & \\
\hline
\end{tabular}

Ca, carcinoma; CR, complete response; PR, partial response; SD, stable disease; PD, progressive disease; CI, confidence interval.

Table III. Actual and relative CBDCA doses.

\begin{tabular}{|c|c|c|c|c|c|c|c|c|c|c|c|c|c|}
\hline \multirow{2}{*}{$\begin{array}{l}\text { CBDCA dose, } \\
\text { mg/body }\end{array}$} & \multirow{2}{*}{$\begin{array}{c}\text { Cycle } \\
\text { no. }\end{array}$} & \multirow{2}{*}{$\begin{array}{l}\text { G-CSF }{ }^{\mathrm{a}}, \\
\text { vials }\end{array}$} & \multicolumn{11}{|c|}{ Dose intensity of CBDCA, cycles } \\
\hline & & & 1 & 2 & 3 & 4 & 5 & 6 & 7 & 8 & 9 & 10 & $>10$ \\
\hline 300 & 4 & 0 & 1 & 1 & 1 & 1 & & & & & & & \\
\hline 360 & 7 & 0 & 1 & 1 & 1 & 1 & 1 & 1 & 1 & & & & \\
\hline 400 & 2 & 16 & 1 & 1 & & & & & & & & & \\
\hline 400 & 3 & 11 & 1 & 1 & 1 & & & & & & & & \\
\hline 400 & 4 & 12 & 1 & 1 & 1 & 1 & & & & & & & \\
\hline 420 & 2 & 7 & 1 & 0.75 & & & & & & & & & \\
\hline 420 & 3 & 0 & 1 & 1 & 1 & & & & & & & & \\
\hline 450 & 4 & 12 & 1 & 1 & 1 & 1 & & & & & & & \\
\hline 450 & 7 & 8 & 1 & 1 & 1 & 1 & 0.75 & 0.75 & 0.75 & & & & \\
\hline 450 & 10 & 39 & 1 & 1 & 0.75 & 0.75 & 0.75 & 0.75 & 0.75 & 0.75 & 0.75 & 0.75 & \\
\hline 450 & 7 & 12 & 1 & 1 & 1 & 0.75 & 0.75 & 0.75 & 0.75 & & & & \\
\hline 450 & 10 & 21 & 1 & 1 & 1 & 1 & 1 & 1 & 1 & 1 & 1 & 1 & \\
\hline 450 & 11 & 32 & 1 & 1 & 1 & 1 & 1 & 1 & 1 & 1 & 1 & 1 & 1 \\
\hline 450 & 12 & 53 & 1 & 1 & 1 & 1 & 1 & 1 & 1 & 1 & 1 & 0.75 & 0.75 \\
\hline 460 & 6 & 34 & 1 & 0.75 & 0.75 & 0.75 & 0.75 & 0.75 & & & & & \\
\hline 480 & 2 & 14 & 1 & 1 & & & & & & & & & \\
\hline 500 & 2 & 9 & 1 & 1 & & & & & & & & & \\
\hline 500 & 2 & 0 & 1 & 1 & & & & & & & & & \\
\hline 500 & 4 & 6 & 1 & 1 & 1 & 1 & & & & & & & \\
\hline 550 & 3 & 0 & 1 & 1 & 1 & & & & & & & & \\
\hline 585 & 4 & 7 & 1 & 1 & 1 & 1 & & & & & & & \\
\hline
\end{tabular}

${ }^{a} 50 \mu \mathrm{g}$ G-CSF/vial. CBDCA, carboplatin; G-CSF, granulocyte colony-stimulating factor.

The actual and relative dose intensities of CBDCA are shown in Table III. The cycle number and the total number of G-CSF injections for each patient are also shown. Dose reduction was necessary in six patients. Neutropenia was the only toxicity for which dose reduction was required (Table IV). No patient experienced a dose reduction for any reason other than grade 4 
Table IV. Toxicity in patients with National Cancer Institute's Common Toxicity Criteria for Adverse Events (most severe, any course).

\begin{tabular}{|c|c|c|c|c|c|c|}
\hline \multirow[b]{2}{*}{ Toxicity } & \multicolumn{4}{|c|}{ Grade } & \multirow{2}{*}{$\begin{array}{l}\text { Total, } \\
\text { n }(\%)\end{array}$} & \multirow{2}{*}{$\begin{array}{c}\geq \text { Grade } 3, \\
\mathrm{n}(\%)\end{array}$} \\
\hline & 1 & 2 & 3 & 4 & & \\
\hline Neutropenia & 0 & 2 & 7 & 10 & $19(90.5)$ & $17(81.0)$ \\
\hline Leukocytopenia & 2 & 2 & 11 & 3 & $18(85.7)$ & $14(66.7)$ \\
\hline Febrile neutropenia & 0 & 0 & 4 & 0 & $4(19.0)$ & $4(19.0)$ \\
\hline Thrombocytopenia & 4 & 1 & 3 & 0 & $8(38.1)$ & $3(14.3)$ \\
\hline Infection & 0 & 0 & 1 & 0 & $1(4.8)$ & $1(4.8)$ \\
\hline Anemia & 6 & 7 & 1 & 0 & $14(66.7)$ & $1(4.8)$ \\
\hline Alopecia & 9 & 11 & 0 & 0 & $20(95.2)$ & $0(0.0)$ \\
\hline Nausea & 8 & 2 & 0 & 0 & $10(47.6)$ & $0(0.0)$ \\
\hline Vomiting & 2 & 1 & 0 & 0 & $3(14.3)$ & $0(0.0)$ \\
\hline Diarrhea & 2 & 2 & 0 & 0 & $4(19.0)$ & $0(0.0)$ \\
\hline Ileus & 0 & 0 & 0 & 0 & $0(0.0)$ & $0(0.0)$ \\
\hline Allergic reaction & 1 & 0 & 0 & 0 & $1(4.8)$ & $0(0.0)$ \\
\hline Neuropathy & 1 & 0 & 0 & 0 & $1(4.8)$ & $0(0.0)$ \\
\hline Pneumonitis & 0 & 0 & 0 & 0 & $0(0.0)$ & $0(0.0)$ \\
\hline AST & 1 & 3 & 0 & 0 & $4(19.0)$ & $0(0.0)$ \\
\hline ALT & 1 & 3 & 0 & 0 & $4(19.0)$ & $0(0.0)$ \\
\hline Alkaline phosphatase & 1 & 1 & 0 & 0 & $2(9.5)$ & $0(0.0)$ \\
\hline Bilirubin & 0 & 0 & 0 & 0 & $0(0.0)$ & $0(0.0)$ \\
\hline Liver failure & 0 & 0 & 0 & 0 & $0(0.0)$ & $0(0.0)$ \\
\hline
\end{tabular}

AST, aspartate transaminase; ALT, alanine transaminase.

neutropenia. Grade 3/4 neutropenia was observed in 17 patients $(81.0 \%)$, grade $3 / 4$ leukocytopenia in $14(66.7 \%)$, grade 3 thrombocytopenia in three $(14.3 \%)$ and grade 3 anemia in one patient (4.8\%). Neither grade 4 thrombocytopenia nor grade 4 anemia occurred. Febrile neutropenia was observed in four patients. All these patients were successfully managed with G-CSF and broad-spectrum antibiotics. The patients with neutropenia recovered with G-CSF administration, however, one patient with a perirectal abscess deteriorated while neutropenic. This infection was successfully treated with broad-spectrum antibiotics. No thrombopenic episodes were complicated by hemorrhage. Alopecia was almost universal (95.2\%), and grade 1/2 nausea was observed in 10 patients $(47.6 \%)$, whereas grade $1 / 2$ vomiting was observed in three (14.3\%). Grade $1 / 2$ diarrhea occurred in four patients (19.0\%) and a grade 1 allergic reaction in one $(4.8 \%)$. Neuropathy, i.e., paresthesia with a loss of vibration sensation, occurred in only one patient. None of the patients developed pneumonitis or interstitial pneumonia. Grade 1/2 elevations of hepatic enzymes were observed in four (AST), four (ALT) and two (alkaline phosphatase) patients and these levels normalized without medication. None of the patients showed nephrotoxicity and there were no treatment-related mortalities.

\section{Discussion}

The present study retrospectively analyzed the continuation of first-line treatment with docetaxel and CBDCA in advanced NSCLC patients. The continuation of this first-line treatment for disease control was possible, as the only cumulative toxicity was neutropenia. The median number of cycles was, however, four (range, 2-12 cycles), the same as the ASCO recommendations (7). This continuous combination therapy may have encouraging activity for the treatment of stage IV adenocarcinoma, although not for stage IV non-adenocarcinoma, including the poorly-differentiated type. In the treatment of the adenocarcinoma patients of the present study, the RR of $64.3 \%$, the median PFS time of 210 days, the median survival time of 490 days and the one-year survival rate of $71.4 \%$ were encouraging. Among the adenocarcinoma patients who received $\geq 10$ cycles, long-term survival durations were achieved. Despite tumor persistence, neither tumor regrowth nor progression occurred until the terminal stage in these patients. The feasibility of the CBDCA-based combination with docetaxel makes multiple administrations possible without serious side-effects, including nausea/vomiting and nephrotoxicity, which often develop in patients receiving CDDP-based combinations, or the cumulative muscle pain and neurotoxicity observed in those who receive paclitaxel.

Regarding the cycle number for first-line treatment, a few studies have confirmed the non-inferiority, in terms of the OS time, of three to four cycles compared with six cycles of chemotherapy $(19,20)$. However, a study by Soon et al (21) reported that extending chemotherapy beyond a standard number of cycles significantly improved the PFS time in a meta-analysis of 13 randomized-controlled trials involving $>3,000$ patients. A cycle number exceeding six could be administered in certain patients, particularly those with adenocarcinoma, according to individual PS and the 
side-effects of this protocol. The profiles of toxicities occurring in the first cycle were almost the same as those in the subsequent cycles. Toxicities, which had not been observed in the first several cycles, were not cumulative.

Limitations of the present retrospective results, obtained in clinical settings, include the small number of patients and the lack of epidermal growth factor receptor mutation status and echinoderm microtubule-associated protein-like 4 anaplastic lymphoma kinase fusion gene status. However, determination of these genetic features was not possible between 1999 and 2003. With this treatment protocol, as performed at Saiseikai Central Hospital (Tokyo, Japan) prior to 2003 , the CBDCA dose was determined based on the body surface area (BSA), rather than by the AUC, and the CBDCA dose was $300 \mathrm{mg} / \mathrm{m}^{2}$, which is the dose approved by the Japanese Ministry of Health, Labour and Welfare. Therefore, Calvert's formula was used to calculate the corresponding AUC, employing the measured creatinine clearance. The mean calculated AUC was $4.4 \mathrm{mg} / \mathrm{ml} \times$ min, which was low compared with the TAX 326 study, a phase III study of docetaxel combined with a platinum agent (22). In the TAX 326 study, the AUC was $6 \mathrm{mg} / \mathrm{ml} \times$ min for CBDCA, and the docetaxel dose was $75 \mathrm{mg} / \mathrm{m}^{2}$.

Neutropenia was a serious issue, and numerous G-CSF administrations were necessary in patients receiving this continuation therapy of docetaxel and CBDCA. No other toxicities were serious. Despite the relatively low administered doses of docetaxel and CBDCA, 17 patients (81.0\%) experienced grade 3/4 neutropenia. These patients were successfully managed with G-CSF and a dose reduction. No grade 3/4 toxicities, other than myelosuppression, were observed. Alopecia was almost universal, but not serious. Nausea, vomiting and diarrhea were moderate, but manageable. There were no serious allergic reactions. Neuropathy, which often occurs with paclitaxel administration, was rare and mild. Due to these tolerable toxicity profiles and as hydration was not necessary, patients with renal impairment (creatinine clearance, $40-50 \mathrm{ml} / \mathrm{min}$ ) were successfully treated with this regimen.

Continuous first-line chemotherapy with docetaxel $\left(60 \mathrm{mg} / \mathrm{m}^{2}\right)$ and CBDCA $\left(300 \mathrm{mg} / \mathrm{m}^{2}\right)$, as determined by BSA rather than AUC, may be effective in advanced NSCLC patients with adenocarcinoma. In the present study, the doses of docetaxel and CBDCA were set relatively low, compared with the majority of previously reported studies, and administered as many times as possible. The rate of neutropenia was high however, possibly making prophylactic G-CSF administration necessary. Further investigations of the optimal cycle numbers are warranted.

\section{References}

1. Ferlay J, Shin HR, Bray F, Forman D, Mathers C and Parkin DM GLOBOCAN 2012: Estimated cancer incidence, mortality and prevalence worldwide in 2012. http://globocan.iarc.fr/ Pages/fact_sheets_population.aspx. Accessed February 20, 2014.

2. Parkin DM, Bray F, Ferlay J and Pisani P: Global cancer statistics, 2002. CA Cancer J Clin 55: 74-108, 2005.

3. No authors listed: Chemotherapy in non-small cell lung cancer: a meta-analysis using updated data on individual patients from 52 randomised clinical trials. Non-small Cell Lung Cancer Collaborative Group. BMJ 311: 899-909, 1995.
4. Azzoli CG, Baker S Jr, Temin S, Pao W, Aliff T, Brahmer J, Johnson DH, Laskin JL, Masters G, Milton D, Nordquist L, Pfister DG, Piantadosi S, Schiller JH, Smith R, Smith TJ, Strawn JR, Trent D and Giaccone G; American Society of Clinical Oncology: American Society of Clinical Oncology clinical practice guideline update on chemotherapy for stage IV non-small-cell lung cancer. J Clin Oncol 27: 6251-6266, 2009.

5. National Comprehensive Cancer Network: Clinical practice guidelines in oncology: non-small cell lung cancer, version 2,2012. http://www.nccn.org/professionals/physician_gls/pdf/nscl.pdf. Accessed August 10, 2013.

6. Socinski MA, Schell MJ, Peterman A, Bakri K, Yates S, Gitten R, Unger P, Lee J, Lee JH, Tynan M, Moore M and Kies MS: Phase III trial comparing a defined duration of therapy versus continuous therapy followed by second-line therapy in advanced-stage IIIB/IV non-small-cell lung cancer. J Clin Oncol 20: 1335-1343, 2002.

7. Azzoli CG, Temin S, Aliff T, Baker S Jr, Brahmer J, Johnson DH, Laskin JL, Masters G, Milton D, Nordquist L, Pao W, Pfister DG, Piantadosi S, Schiller JH, Smith R, Smith TJ, Strawn JR, Trent D and Giaccone G; American Society of Clinical Oncology: 2011 focused update of 2009 American Society of Clinical Oncology clinical practice guideline update on chemotherapy for stage IV non-small-cell lung cancer. J Clin Oncol 29: 3825-3831, 2011.

8. Brodowicz T, Krzakowski M, Zwitter M, Tzekova V, Ramlau R, Ghilezan N, Ciuleanu T, Cucevic B, Gyurkovits K, Ulsperger E, Jassem J, Grgic M, Saip P, Szilasi M, Wiltschke C, Wagnerova M, Oskina N, Soldatenkova V, Zielinski C and Wenczl M; Central European Cooperative Oncology Group CECOG: Cisplatin and gemcitabine first-line chemotherapy followed by maintenance gemcitabine or best supportive care in advanced non-small cell lung cancer: a phase III trial. Lung Cancer 52: 155-163, 2006.

9. Paz-Ares L, de Marinis F, Dediu M, Thomas M, Pujol JL, Bidoli P, Molinier O, Sahoo TP, Laack E, Reck M, Corral J, Melemed S, John W, Chouaki N, Zimmermann AH, Visseren-Grul C and Gridelli C: Maintenance therapy with pemetrexed plus best supportive care versus placebo plus best supportive care after induction therapy with pemetrexed plus cisplatin for advanced non-squamous non-small-cell lung cancer (PARAMOUNT): a double-blind, phase 3, randomized controlled trial. Lancet Oncol 13: 247-255, 2012.

10. Pérol M, Chouaid C, Pérol D, Barlési F, Gervais R, Westeel V, Crequit J, Léna $\mathrm{H}$, Vergnenègre $\mathrm{A}$, Zalcman $\mathrm{G}$, Monnet I, Le Caer H, Fournel P, Falchero L, Poudenx M, Vaylet F, Ségura-Ferlay C, Devouassoux-Shisheboran M, Taron M and Milleron B: Randomized, phase III study of gemcitabine or erlotinib maintenance therapy versus observation, with predefined second-line treatment, after cisplatin-gemcitabine induction chemotherapy in advanced non-small-cell lung cancer. J Clin Oncol 30: 3516-3524, 2012.

11. Fidias PM, Dakhil SR, Lyss AP, Loesch DM, Waterhouse DM, Bromund JL, Chen R, Hristova-Kazmierski M, Treat J, Obasaju CK, Marciniak M, Gill J and Schiller JH: Phase III study of immediate compared with delayed docetaxel after front-line therapy with gemcitabine plus carboplatin in advanced non-small-cell lung cancer. J Clin Oncol 27: 591-598, 2009.

12. Ciuleanu T, Brodowicz T, Zielinski C, Kim JH, Krzakowski M, Laack E, Wu YL, Bover I, Begbie S, Tzekova V, Cucevic B, Pereira JR, Yang SH, Madhavan J, Sugarman KP, Peterson P, John WJ, Krejcy K and Belani CP: Maintenance pemetrexed plus best supportive care versus placebo plus best supportive care for non-small-cell lung cancer: a randomized, double-blind, phase 3 study. Lancet 374: 1432-1440, 2009.

13. Cappuzzo F, Ciuleanu T, Stelmakh L, Cicenas S, Szczésna A, Juhász E, Esteban E, Molinier O, Brugger W, Melezínek I, Klingelschmitt G, Klughammer B and Giaccone G; SATURN investigators: Erlotinib as maintenance treatment in advanced non-small-cell lung cancer: a multicentre, randomised, placebo-controlled phase 3 study. Lancet Oncol 11: 521-529, 2010.

14. Takeda K, Hida T, Sato T, Ando M, Seto T, Satouchi M, Ichinose Y, Katakami N, Yamamoto N, Kudoh S, Sasaki J, Matsui K, Takayama K, Kashii T, Iwamoto Y, Sawa T, Okamoto I, Kurata T, Nakagawa K and Fukuoka M: Randomized phase III trial of platinum-doublet chemotherapy followed by gefitinib compared with continued platinum-doublet chemotherapy in Japanese patients with advanced non-small-cell lung cancer: results of a west Japan thoracic oncology group trial (WJTOG0203). J Clin Oncol 28: 753-760, 2010. 
15. Zhang L, Ma S, Song X, Han B, Cheng Y, Huang C, Yang S, Liu X, Liu Y, Lu S, Wang J, Zhang S, Zhou C, Zhang X, Hayashi $\mathrm{N}$ and Wang $\mathrm{M}$; INFORM investigators: Gefitinib versus placebo as maintenance therapy in patients with locally advanced or metastatic non-small-cell lung cancer (INFORM; C-TONG 0804): a multicentre, double-blind randomized phase 3 trial. Lancet Oncol 13: 466-475, 2012.

16. Pfister DG, Johnson DH, Azzoli CG, Sause W, Smith TJ, Baker S Jr, Olak J, Stover D, Strawn JR, Turrisi AT and Somerfield MR; American Society of Clinical Oncology: American Society of Clinical Oncology treatment of unresectable non-small-cell lung cancer guideline: update 2003. J Clin Oncol 22: 330-353, 2004.

17. Therasse P, Arbuck SG, Eisenhauer EA, Wanders J, Kaplan RS, Rubinstein L, Verweij J, Van Glabbeke M, van Oosterom AT, Christian MC and Gwyther SG: New guidelines to evaluate the response to treatment in solid tumors. European Organization for Research and Treatment of Cancer, National Cancer Institute of the United States, National Cancer Institute of Canada. J Nat Cancer Inst 92: 205-216, 2000.

18. Cancer Therapy Evaluation Program: Common Terminology Criteria for Adverse Events (CTCAE). Version 3.0, DCTD, NCI, NIH, DHHS, 2006. http://ctep.cancer.gov/protocolDevelopment/electronic_applications/docs/ctcaev3.pdf. Accessed August 10, 2013.
19. von Plessen C, Bergman B, Andresen O, Bremnes RM, Sundstrom S, Gilleryd M, Stephens R, Vilsvik J, Aasebo U and Sorenson S: Palliative chemotherapy beyond three courses conveys no survival or consistent quality-of-life benefits in advanced non-small-cell lung cancer. Br J Cancer 95: 966-973, 2006.

20. Park JO, Kim SW, Ahn JS, Suh C, Lee JS, Jang JS, Cho EK, Yang SH, Choi JH, Heo DS, Park SY, Shin SW, Ahn MJ, Lee JS, Yun YH, Lee JW and Park K: Phase III trial of two versus four additional cycles in patients who are nonprogressive after two cycles of platinum-based chemotherapy in non small-cell lung cancer. J Clin Oncol 25: 5233-5239, 2007.

21. Soon YY, Stockler MR, Askie LM and Boyer MJ: Duration of chemotherapy for advanced non-small-cell lung cancer: a systematic review and meta-analysis of randomized trials. J Clin Oncol 27: 3277-3283, 2009.

22. Fossella F, Pereira JR, von Pawel J, Pluzanska A, Gorbounova V, Kaukel E, Mattson KV, Ramlau R, Szczesna A, Fidias P, Millward M and Belani CP: Randomized, multinational, phase III study of docetaxel plus platinum combinations versus vinorelbine plus cisplatin for advanced non-small-cell lung cancer: the TAX 326 study group. J Clin Oncol 21: 3016-3024, 2003. 